\title{
PENELITIAN PENINGKATAN MUTU UNTUK MENDAPATKAN HASIL UJI TEGANGAN PUTUS SETELAH AGING DAN PERPANJANGAN PUTUS SEBELUM AGING KOMPON KARET BANTALAN DERMAGA YANG MEMENUHI SII 2281 - 88
}

\author{
Oleh : Suprapto
}

\begin{abstract}
This research was aimed at gaining the compound rubber of dock Vender formula which has the characteristic of optimal tensile strength after aging $70 \pm 1^{\circ} \mathrm{C}$ within $3 \times 24$ hours and the optimal elongation at break before aging. This research used the amaount of carbon black formula with variation : 40,45,50,55,60,65, and 70 parts for each 100 partsof rubber. The research showed that using the formula $40: 100$, the optimal tensile strength after aging $70 \pm 1^{\circ} \mathrm{C}$ during $3 \times 24$ hours resulted the average tensile strength 19,79 newton/ $\mathrm{mm} 2$. Where as the characteristic of the optimum elongation at break was gained at formula 40 part with the average elongation break $682,98 \%$. The result showed that that the elongation break after aging and elongation at break after aging fulfilled the specification of SII 228188 dock Vender.
\end{abstract}

\section{INTISARI}

Penelitian ini bertujuan untuk mendapatkan formula kompon karet bantalan dermaga yang mempunyai sifat tegangan putus setelah aging $70 \pm 1^{\circ} \mathrm{C}$ selana $3 \times 24$ jam yang optimal. dan perpanjangan putus sebelum aging yang optimal. Dalam penelitian ini digunakan formula jumlah karbon black dengan variasi 40,45,50,55, 60, 65 dan 70 bagian untik setiap 100 bagian karet. Hasil penelitian ini menunjukkan bahwa tegangan putus setelah aging $70 \pm 1^{\circ} \mathrm{C}$ selama $3 \times 24$ jam optimal pada penggunaan carbon black 40 bagian dengan tegangan putus rata-rata $19,79 \mathrm{~N} / \mathrm{mm}^{2}$. Sedangkan sifat perpanjangkan putus sebetum aging nilai optimum didapat pada formula carbon black 40 bagian dengan perpanjangam putus rata-rata $682,98 \%$. HAsil uji tegangan putus setelah aging dan perpanjangan putus sebelum aging memenuhi persyaratan SII 2281-88 bantalan karet untuk dermaga.

\section{PENDAHULUAN}

Pada saat ini industri-industri karet telah berkembang dengan pesatnya, sejalan dengan pesatnya, sejalan dengan usaha pemerintah untuk meningkatkan eksport karet mentah ke ekspor produk jadi yang akan memberikan nilai tambah 
bagi devisa negara. Produk-produk karet telah dibuat di Indonesia antara lain mainan anak-anak, sil pintu air, bantakan karet jembatan, slang radiator, slang untuk bensin, sil karet untuk sepeda motor dan mobil, bantalan dermaga dan sebagainya.Bantalan karet dermaga merupakan salah satu dari produk teknik karet yang dibuat di Indonesia, untuk pembangunan pelabuhan-pelabuhan dan berfungsi untuk menghindari benturan langsung antara kapal dengan dinding pelabuhan pada waktu kapal merapat dalam ringka bongkar muat barang, sehingga baik kapal maupun dermaga tidak mudah rusak. Agar fungsi tersebut dapat dipenuhi, maka bantalan karet dermaga harus mempunyai sif at yang baik antara lain tegangan putus dan perpanjangan putus. Untuk pengujian tersebut telah ditetapkan persyaratanpersyaratan teknis karet sesuai SII No. 2281-88, Bantalan Karet Untuk Dermaga Penelitian ini dimaksudkan untuk mendapatkan formulasi kompon yang mutunya dapat memehuni persyaratan SII 2281-88, bantalan karet untuk dermaga.

\section{MATERI DAN METODA}

Materi Penelitian

\section{a. Bahan}

Bahan yang digunakan dalam penelitian ini adalah

1. Rubber Smoke Sheet (RSS)

2. Karet Sintetis 1502 (SBR 1502)

3. AOSP

4. Sulfemanida (CBS)

5. Carbon Black

6. Napthonic oil

7. Zink oksida

8. Asam stearat

9. Guanidine (I)PG)

10. Sulfur

b. Alat

Alat yang digunakan dalam penelitian ini adalah

1. Neraca analitis

2. Two Roll mill

3. Cetakan slap

4. Hidrolik press

5. Stop watch

6. Pisau pons untuk tegangan putus dan perpanjangan putus, pisau, penggaris dan gunting.

7. Mesin tensile strength.
Metode Penelitian

a. Proses pembuatan kompon

Tahapan pembuatan kompon karet bantalau dermaga adalah sebagai berikut : Penimbangan bahan

Bahan-bahan ditimbang dengan neraca analitis sesuai dengan formulasi dengan variasi carbon black sehagai berikut

\begin{tabular}{|c|c|c|c|c|c|c|c|c|}
\hline \multirow{2}{*}{ Momen } & \multirow{2}{*}{ Nama Bahan } & \multicolumn{7}{|c|}{ Jumlah formulasi (Bagian) } \\
\hline & & I & II & III & IV & V & VI & VII \\
\hline 1. & RSS & 100 & I(K) & 100 & $I(x)$ & 100 & 100 & 100 \\
\hline 2. & SBR 1.502 & 20 & 20 & 20 & 20 & 20 & 20 & 20) \\
\hline 3. & Napthonic oil & 5 & 5 & 5 & 5 & 5 & 5 & 5 \\
\hline 4. & Kink oksida & 5 & 5 & 5 & 5 & 5 & 5 & 5 \\
\hline 5. & Carbon black & 40 & 45 & 50 & .55 & 69 & 6.5 & 70 \\
\hline 6. & AOSP & 1 & 1 & 1 & 1 & 1 & 1 & 1 \\
\hline 7. & Asam stearat & 1,5 & 1,5 & 1,5 & 1,5 & 1,5 & 1,5 & 1,5 \\
\hline 8. & Sulfenamida & 1,2 & 1,2 & 1,2 & 1,2 & 1,2 & 1,2 & 1,2 \\
\hline 9. & Guanidine & 0,4 & 0,4 & 0,4 & 0,4 & 0,4 & 0,4 & 0,4 \\
\hline 10. & Sulfur & 2,5 & 2,5 & 2,5 & 2,5 & 2,5 & 2,5 & 2,5 \\
\hline
\end{tabular}

\section{Penggilingan}

1. Hidupkan mesin two roll mill dan panaskan rol hagian atas dan bawah pada suhu $50^{\circ}$ ( $\therefore$ I alu masukkan bahan jaret RSS, kemudian giling sampai plastis.

2. Masukkan SBR 1502 dan giling sampai plastis, karet mengalami proses mastikasi, sehingga karet menjadi plastis dan lunak.

3. Setelah bahan baku karet menjadi lunak dan plastis, kemudian masukkan berturut turut asam stearat, ZNO, Napthonic oil, carbon black, AOSP, DPG, ( BS, dan digiling sampai plastis

4. Pada tahap terakhir tambahkan sulfur sebagai bahan vulkanisasi, dan digiling sampai homogen. Komponen yang didapat dalam bentuk lembaran dengan ketchalan $2 / \mathrm{mm}$, dan kemudian kondisikan dalam ruangan pada suhu $23^{\circ} \pm 2^{\circ} \mathrm{C}$ dan kelembaban $65 \pm 5 \%$ selama 24 jam

\section{Proses Vulkanisasi}

Pembuatan slep dimaksudkan untuk pembuatan lembaran contoh, yang akan diuji sckaligus kompon mengalami pematangan atau vulkanisasi. Sebelum kompon divulkanisasi atau difontuk skep, terlebih dahulu kompon dilakukan curing time dengan alat Showbury curometer untuk mengetahui tingkat kematangan kompon katret dengan suhu waktu yang optimum. 
Adapun cara pembuatan slep adalah sebagai berikut

1. Kompon yang sudah dikondisikan dan dicurometer ditimbang sebanyak $\pm 80 \mathrm{gr}$ untuk membuat slep dengan tebal $2 \mathrm{mM}$ untuk contoh uji tegangan putus dan per panjangan putus.

2. Kompon yang sudah ditimbang diletakkan dalam plat cetakan yang tebalnya 2 $\mathrm{mm}$, kemudian ditutup dengan plat stainless steel yang dilapisi alumunium foil

3. Kemudian masukkan dalam alat hidraulik press, pada suhu dan waktu sesua dengan tekanan $150 \mathrm{~kg} / \mathrm{cm}^{2}$

4. Setelah suhu dan waktu sesuai dengan curing time, pemanasan dihentikan dan didinginkan samapi suhu $\pm 60^{\circ} \mathrm{C}$ tekanan dilepas dan slep dikeluarkan dari alat hidraulik press

\section{b. Pengujian}

Hasil vulkanisasi dalam bentuk slep dikondisikan dalam ruangan kondisi pada suhu $23^{\circ} \mathrm{C}+2^{\circ} \mathrm{C}$ dan kelembaban $65 \pm 5 \%$ selama 24 jam.

1. Setelah contoh uji dipotong dengan pisau pons sesuai dengan standar, beri 2 garis sejajar pada cuplikan berjarak : 25,4 mm dan ukur lebar dan tebal cuplikan dibagian yang sempit 3 kali ulangan dan hasilnya dirata-ratakan.

2. Pasang cuplikan pada penjepit alat tensile strength, yaitu kedua ujungnya dijepit hingga jarak jepitnya $50 \mathrm{~mm}$.

3. Jalankan mesin dengan kecapatan sesuai dengan standar hingga cuplikan terputus 4. Catat panjang cuplikan pada waktu putus.

\section{HASIL PENELITIAN DAN PEMBAHASAN}

Dari tiga kali hasil pengujian terhadap uji tegangan putus setelah aging dan perpanjangan putus karet bantalan untuk dermaga terlihat seperti pada tabel 1 dan tabel 2.

Tabel 1 : Data Hasil Uji Tegangan Putus Setelah Aging $\left(70^{\circ} \pm 1^{\circ} \mathrm{C}, 3 \times 24\right.$ jam $)$

\begin{tabular}{|c|c|c|c|c|c|c|c|c|}
\hline \multirow{2}{*}{$\begin{array}{c}\text { Ulang } \\
\text { an }\end{array}$} & \multicolumn{7}{|c|}{ Kompon } & \multirow{2}{*}{ Total } \\
\hline & I & II & III & IV & V & VI & VII & \\
\hline I & 20,96 & 19,75 & 17,22 & 16,71 & 18,27 & 18,83 & 17,79 & \\
\hline II & 19,31 & 19,85 & 17,30 & 16,66 & 19.29 & 19,43 & 15,85 & \\
\hline III & 19,10 & 18,62 & 16,89 & 19,66 & 18,95 & 18,32 & 18,33 & \\
\hline Total & 59,37 & 58,41 & 51,41 & 53,03 & 56,51 & 56,58 & 51,97 & \\
\hline $\begin{array}{l}\text { Rata- } \\
\text { rata }\end{array}$ & 19,79 & 19.41 & 17.14 & 17,68 & 18,84 & 18,86 & 17,32 & 387.09 \\
\hline
\end{tabular}

Tabel 2 : Data Hasil I ji Perpanjangan Putus \% Sebelum Aging

\begin{tabular}{|c|c|c|c|c|c|c|c|l|}
\hline \multirow{2}{*}{$\begin{array}{c}\text { Ulang } \\
\text { an }\end{array}$} & \multicolumn{7}{|c|}{ Kompon } & \multirow{2}{*}{ Total } \\
\cline { 2 - 9 } & II & III & IV & V & VI & VII & \\
\hline I & 680,85 & 617,02 & 563,83 & 517,02 & 478,72 & 521,28 & 457,45 & \\
\hline II & 687,23 & 591,28 & 548,94 & 585,11 & 597,87 & 578,72 & 404,26 & \\
\hline III & 680,85 & 617,02 & 459,57 & 534,14 & 508,51 & 502,12 & 425,53 & \\
\hline Total & 2048,93 & 1825,32 & 1572,34 & 1636,27 & 1565,10 & 1602,12 & 1287,24 & \\
Rata- & & & & & & & & \\
\hline
\end{tabular}

Untuk mengetahui hasil penelitian kompon karet untuk bantalan dermaga yang mempunyai sifat tegangan putus setelah aging dan perpanjangan putus sebelum aging yang optium maka perlu dilakukan analisa statistik dengan Methode Simple Factorial dan dilanjutkan keanalisa LSD.

a .Analisa statistik untuk tegangan putus setelah aging $70^{\circ} \pm 1^{\circ} \mathrm{C}$ selama $3 \times 24 \mathrm{jam}$

Tabel 3: Tabel Anova untuk Uji tegangan putus Setelah Aging Kompon Bantalan Karet untuk Dermaga

\begin{tabular}{|l|c|c|c|c|c|}
\hline \multicolumn{1}{|c|}{ S.V } & DF & SS & MS & F cal & F 5\% \\
\hline Treatment & 6 & 19,86 & 3,31 & & \\
Error & 14 & 13,54 & 0,97 & 3,41 & 2,85 \\
\hline Total & 20 & 33,40 & & & \\
\hline
\end{tabular}

Dari perhitungan hasil uji pada tabel 3 diatas, menunjukan perhitungan bahwa tegangan putus setelah aging untuk bantalan karet dermaga untuk setiap perlakuan diantara kompon yang satu dengan kompon yang lainnya ada perbedaan yang nyata Kesimpulan in terlihat dari $\mathrm{F}$ hitung lebih besar dari pada $\mathrm{F}$ tabel

Kemudian untuk mengetahui sifat tegangan putus setelah aging kompon bantalan karet untuk dermaga yang paling optimum digunakan analisa LSD 
Tabel : 4 Tabel LSD 5\% Kompon Karet Untuk Bantalan Dermaga

\begin{tabular}{|c|c|c|c|}
\hline Treatment & Hasil Total & Hasil Rata-rata & $\begin{array}{c}\text { Notasi dengan } \\
\text { LSD 5\% }\end{array}$ \\
\hline III & 51,41 & 17,14 & a \\
\hline VII & 51,97 & 17,32 & a b \\
\hline IV & 53,03 & 17,68 & a b \\
\hline V & 56,51 & 18,84 & $\mathrm{c}$ \\
\hline VI & 56,58 & 18,86 & $\mathrm{c}$ \\
\hline II & 58,22 & 19,41 & $\mathrm{c}$ \\
\hline I & 59,37 & 19,79 & \\
\hline
\end{tabular}

Dari perhitungan hasil uji tegangan putus setelah aging kompon karet bantanlan dermaga pada tabel 4 bahwa : kenaikan dari jumlah carbon black yang ditambahkan dengan interval 5 bagian diatas formulasi VII dengan jumlah karbon black 70 bagian, formulasi III dengan jumlah karbon black 50 bagian ,formulasi IV dengan jumlah karbon 55 bagian, formulasi V dengan jumlah karbon black 60 bagian, dan formula VI dengan jumlah karbon black 65 bagian tidak berbeda nyata untuk jenis tegangan putusnya. Akan tetapi kompon tersebut mempunyai perbedaan yang nyata dengan kompon formula I dengan jumlah formula II dengan jumlah karbon black 45 bagian. Untuk uji tegangan putus setelah aging kompon yang paling baik adalah formula I dengan jumlah carbon black 40 bagian, dengan hasil tegangan putus rata-rata dari $3 \times$ ulangan $19,79 \mathrm{~N} / \mathrm{mm}^{2}$ atau perubahan maksimal $1,81 \%$. Memenuhi persyaratan SII No, 2288 - 1988 bantalan karet untuk dermaga a. Sedangkan yang disyaratkan dalam SII No. 2281 - 1988 bantalan karet untuk dermaga c perubahan maksimal adalah $20 \%$.

b. Analisa Statistik Untuk Perpanjangan Putus
Tabel 5 : Tabel Anova Untuk Uji Perpanjangan Putus Kompon Bantalan Karet Untuk Dermaga

\begin{tabular}{|l|c|c|c|c|c|}
\hline \multicolumn{1}{|c|}{ S.V } & DF & SS & MS & F cal & F 5\% \\
\hline Treatment & 6 & $111.397,80$ & 1856,35 & & \\
Error & 14 & $21.638,83$ & 1545,63 & & 2,85 \\
\hline Total & 20 & $133.036,60$ & & & \\
\hline
\end{tabular}

Dari perhitungan hasil uji perpanjangan putus kompon karet bantalan dermaga pada tabel 5, menunjukkan perhitungan bahwa perpanjangan putus untuk kompon bantalan karet untuk dermaga diantara perlakuan antara kompon yang satu dengan kompon yang lain terdapat perbedaan yang nyata.

Kesimpulan ini terluhat dari $\mathrm{F}$ hitung yang lebih besar dari pada $\mathrm{F}$ tabel. Kemudian untuk mengetahui sifat perpanjangan putus kompon bantalan karet untuk dermaga yang paling optimum digunakan analisa LSD.

Tabel 6 : Tabel LSD 5\% Untuk Uji Coba Perpanjangan Putus Kompon Karet Untuk Bantalan Dermaga

\begin{tabular}{|c|c|c|}
\hline Treatment & Rata-rata & $\begin{array}{c}\text { Notasi dengan } \\
\text { LSD 5\% }\end{array}$ \\
\hline VII & 424,08 & a \\
\hline III & 524,11 & b \\
\hline V & 528,37 & b \\
\hline VI & 534,04 & b \\
\hline IV & 545,42 & b c \\
\hline II & 608,44 & d \\
\hline I & 682,98 & . \\
\hline
\end{tabular}

Dari perhitungan hasil uji perpanjangan putus kompon karet untuk bantalan dermaga pada tabel 5 diatas, menunjukkan perhitungan bahwa : kenaikan dari jumlah carbon black yang ditambahkan dengan interval 5 bagian diatas formulasi VII dengan jumlah carbon black 70 bagian, berbeda nyata dengan formulasi III dengan jumlah carbon black 50 bagian.

Majalah Barang Kulit, Karet dan Plastik 
Formulasi VII dengan jumlah carbon black 70 bagian berbeda nyata dengan formulasi $V$ dengan jumlah carbon black 60 bagian

Formulasi VII dengan jumlah earbon black 70 bagian berbeda nyala dengan formulasi VI dengan jumlah carbon black 65 bagian formulasi VII dengan jumlah carbon black 70 bagian berbeda nyata dengan formulasi IV dengan jumlah carbon black 55 bagian formulasi VII dengan jumlah carbon black 70 bagiau berbeda nyata dengan formulasi II, dengan jumlah carbon black 45 bagian.

Formulasi VII dengan jumlah carbon black 70 bagian berbeda nyala dengan formulasi I, dengan jumlah carbon 40 bagian

Formulasi III dengan jumlah carbon black 50 bagian tidak berbeda nyata dengan formulasi $V$, dengan jumlah carbon black 60 bagian

Formulasi III dengan jumlah carbon black 50 bagian tidak berbeda nyata dengan formulasi VI, dengan jumlah carbon black 65 hagian

Formulasi III dengan jumlah carbon black 50 hagian tidak berbeda nyata dengan formulasi IV, dengan jumlah carbon black 55 bagian

Formulasi 111 dengan jumlah carbon black 50 bagian tidak berbeda nyata dengan formulasi II, dengan jumlah karbon black 45 bagian.

Formulasi III dengan jumlah carbon black 50 bagian tidak berbeda nyata dengan formulasi I, dengan jumlah carbon black 40 bagian.

Formulasi IV dengan jumlah carbon black 55 bagian dan formulasi II dengan jumlah carbon black 45 bagian tidak berbeda nyata, tetapi keduanya berbeda nyata dengan formulasi I, dengan jumalh carbom black 40 bagian.

Perpanjangan putus paling tinggi terdapat pada formula I, dengan jumlah carbon black sebanyak 40 bagian,dengan hasil perpanjangan putus rata-rata dari 3 kali ulangan sebesar $682,98 \%$. Memenuhi persyaratan SII 2281-1988 bantalan karet dermaga Sedangkan yang disyaratkan dalam SII 2281 - 1988 bantalan karet dermaga untuk perpanjangan putus minimal $300 \%$

\section{KESIMPULAN}

Dari 3 kali ulangan dari hasil penelitian diatas dapat disimpulkan :

1. Untuk hasil uji tegangan putus setelah aging $70^{\circ} \mathrm{C} \pm 1^{\circ} \mathrm{C}$ selama $3 \times 24 \mathrm{jam}$ tertinggi didapat pada formulasi 1 , dengan jumlah carbon black 40 bagian. Dengan hasil uji tegangan putus rata-rata $19,79 \mathrm{~N} / \mathrm{mm}^{2}$ dengan perubahan bila dibanding kan sebelun aging $19,22 \mathrm{~N} / \mathrm{mm}^{2}$ atau perubahan $1,81 \%$, sehingga memenuhi persyaratan SII No. 2281 - 1988 bantalan karet untuk dermaga yang disyaratkan perubahan maksimal $20 \%$.

2. Untuk hasil uji perpanjangan putus tertinggi didapat pada formula II, dengan jumlah carbon black 45 bagian. Dengan hasil uji perpanjangan putus rata-rata $682.98 \%$. Sehingga memenuhi persyaratan SII No. 2281 - 1988 bantalan karet untuk dermaga yang diisyaratkan $300 \%$.

Vol. XIV No. 26 Th. $1998 / 1999$

\section{DAFTAR PIISTAKA}

1. Balai Penelitian Perkebunan Bogor, Petunjuk Pembuatan Barang

2. Departemen Perindustrian "SII No. 2281 - 1988" Bantalan Karet Untuk Dermaga Departemen Perindustrian, Jakarta 1988.

3. D. Ingra C. Rubber and Rubber (ioods Industries, Delhi

4. (iupita R.S., Rubber Processing and Tecnology, Delhi.

5 Morton M (1959), Introduction to Rubber Technology, Reinhold Publising Co., New York.

6. Winer, BJ., Statistical Principles In Experimental Design Second Fition, Mc (irwa-Hill Kogakusha, LTD. 